\title{
Staged unifocalization revisited
}

\author{
Yuki Nakamura ${ }^{1}$ and Harold Burkhart ${ }^{2}$ \\ ${ }^{1}$ The University of Oklahoma Health Sciences Center \\ ${ }^{2}$ University of Oklahoma Health Sciences Centre
}

January 25, 2022

\begin{abstract}
Background. A staged thoracotomy unifocalization approach has not been the dominant option over the past 20 years primarily due to the introduction of midline one-stage complete unifocalization. Methods. In this issue of the Journal of Cardiac Surgery, van de Woestijne and colleagues publish their experience over the past 30 years in 39 consecutive patients with "consistent" staged unifocalization through a lateral thoracotomy in patients with pulmonary atresia, ventricular septal defect, and major aortopulmonary collateral arteries (PA/VSD/MAPCA). Results. They report definitive repair completion in $76.3 \%$ of the patients and an overall survival after definitive repair of $96 \%$ at 20 years despite the study period ranging from 1989 to the present. Conclusion. Given the multiple variations one could have with PA/VSD/MPACA, a midline unifocalization approach may not always be possible. Surgeons should be familiar with the lateral thoracotomy unifocalization staged approach to $\mathrm{PA} / \mathrm{VSD} / \mathrm{MAPCA}$.
\end{abstract}

\section{Title Page}

Title

Staged unifocalization revisited

Short Title

Staged unifocalization

\section{Authors}

Yuki Nakamura, MD, Harold M. Burkhart, MD

Institution and Affiliations

Division of Cardiovascular and Thoracic Surgery, University of Oklahoma Health Sciences Center

800 Stanton L. Young Blvd. Suite 9000, Oklahoma City, OK 73104

\section{Corresponding author}

Yuki Nakamura, MD

Division of Cardiovascular and Thoracic Surgery, University of Oklahoma Health Sciences Center 800 Stanton L. Young Blvd. Suite 9000, Oklahoma City, OK 73104

Fax: (405) 271-3288

Telephone: (405) 271-5789

E-mail: Yuki-Nakamura@ouhsc.edu, yukicvs@gmail.com 


\section{Meeting Presentation}

$\mathrm{N} / \mathrm{A}$

\section{Funding for the work}

$\mathrm{N} / \mathrm{A}$

Keywords

Congenital heart disease

\section{Abstract}

Background.

A staged thoracotomy unifocalization approach has not been the dominant option over the past 20 years primarily due to the introduction of midline one-stage complete unifocalization.

Methods.

In this issue of the Journal of Cardiac Surgery, van de Woestijne and colleagues publish their experience over the past 30 years in 39 consecutive patients with "consistent" staged unifocalization through a lateral thoracotomy in patients with pulmonary atresia, ventricular septal defect, and major aortopulmonary collateral arteries (PA/VSD/MAPCA).

Results.

They report definitive repair completion in $76.3 \%$ of the patients and an overall survival after definitive repair of $96 \%$ at 20 years despite the study period ranging from 1989 to the present.

\section{Conclusion.}

Given the multiple variations one could have with PA/VSD/MPACA, a midline unifocalization approach may not always be possible. Surgeons should be familiar with the lateral thoracotomy unifocalization staged approach to PA/VSD/MAPCA.

\section{Text}

In this issue of the Journal of Cardiac Surgery, van de Woestijne and colleagues ${ }^{1}$ describe their experience with "consistent" staged unifocalization through a lateral thoracotomy in patients with pulmonary atresia, ventricular septal defect, and major aortopulmonary collateral arteries (PA/VSD/MAPCA). Over the past 30 years they have applied this strategy in 39 consecutive patients. Thirteen of the 39 patients underwent a central shunt operation to promote growth of a confluent, hypoplastic central pulmonary artery prior to unifocalization. The median age at the first unifocalization was 13 months. In their initial experience, they performed the first unifocalization at a mean age of 5.9 years but evolved to earlier intervention with their current practice being to perform the first unifocalization procedure at the age of 1 year. A total of 66 unifocalization procedures were performed with two early mortalities. Definitive repair was performed in $76.3 \%$ eligible patients (29/38, excluding one patient awaiting definitive repair) with one hospital death $(3.4 \%)$ and another patient requiring opening of a VSD. Seven patients were left palliated after unifocalization procedures. Four of the seven patients passed away during the follow-up. The overall survival after the definitive repair was $96 \%$ at 20 years with a median follow-up of 19 years. Among survivors after definitive repair, all but one were in New York Heart Association Class 1 or 2 at follow-up. Freedom from pulmonary artery intervention after definitive repair was $71 \%, 67 \%$ and $67 \%$ at 5, 10 and 15 years, respectively. The authors concluded that their staged approach was a reasonable strategy for most PA/VSD/MAPCA patients.

This article is unique in that it describes a "consistent" staged thoracotomy unifocalization approach to PA/VSD/MAPCA patients in the current surgical era, a strategy that predominated in the earlier surgical eras. Puga and colleagues ${ }^{2}$ reported their experience utilizing this approach. From 1982 to 1987, 60.5\% $(23 / 38)$ of their patients reached definite repair with one early and one late death. Eight patients were 
still awaiting further unifocalization procedures. The mean intraoperative right ventricular/left ventricular pressure ratio $(\mathrm{pRV} / \mathrm{pLV})$ at the definitive repair was 0.63 . Iyer and colleagues ${ }^{3}$ published their experience with 58 patients from 1979 to 1989. $51.7 \%$ (30/58) of the patients reached definite repair with one early and 3 late deaths. Ten patients were still awaiting further unifocalization procedures, and 12 other patients were deemed unsuitable for definite repair after unifocalization procedures. Ishibashi and colleagues ${ }^{4}$ published their recent experience with staged thoracotomy unifocalization in 2007. In their experience with 113 consecutive PA/VSD/MAPCA patients from 1982 to 2004, definitive repair was performed in $80.5 \%$ $(91 / 113)$ with 5 early and 15 late deaths. From these studies, one could speculate that the results of a staged unifocalization strategy toward definitive repair have been improving over time. The current article definitely supports this with definitive repair completion in $76.3 \%$ of the patients and an overall survival after definitive repair of $96 \%$ at 20 years despite the study period ranging from 1989 to the present. This improvement could be attributed to early recruitment of patients and advanced surgical techniques, such as using autologous tissue where possible and performing intrapulmonary anastomoses to avoid long segments of remaining MAPCAs. ${ }^{1,4}$

Despite the seeming improvement, the staged unifocalization strategy has not been the dominant option over the past 20 years primarily due to the introduction of midline one-stage complete unifocalization by Reddy et $\mathrm{al}^{5}$ in 1995. The Stanford group has adopted and advocated for midline unifocalization in patients with predominantly single-supply MAPCAs. According to the data of 307 patients who underwent their initial procedures at Stanford from 2001 to $2017^{6}, 78.5 \%$ (241/307) patients were treated with the midline unifocalization strategy with $84.6 \%(204 / 241)$ of them undergoing single-stage definitive repair with a mean $\mathrm{pRV} / \mathrm{pLV}$ of 0.36 . Overall, $93.0 \%$ (280/301) of their eligible patients achieved definitive repair. Staged thoracotomy unifocalization was performed in only $2(0.7 \%)$ of their patients. In their experience, unifocalization revision was necessary for $18.4 \%$ of the patients who underwent the midline unifocalization. ${ }^{7}$

Another strategy in these patients that has been promoted by the Melbourne group over the past 20 years is pulmonary artery rehabilitation without unifocalization. ${ }^{8}$ This concept stemmed from a review of their own patients who had the staged unifocalization strategy. ${ }^{9}$ Recently, they reported their experience from 2003 to $2014 .{ }^{10}$ Among 37 patients, $11 \%$ (4/37) of the patients with heart failure and large MAPCAs underwent one-stage definitive repair with unifocalization. Among 30 eligible patients who entered into the pulmonary artery rehabilitation strategy, $73.3 \%(22 / 30)$ of the patients reached definitive repair, whereas failure of the strategy occurred in 5 patients who either needed unifocalization procedures or were left palliated. Overall, $76.5 \%(26 / 34)$ of their eligible patients reached definitive repair. A lesson from these institutions where either midline one-stage complete unifocalization or the pulmonary artery rehabilitation strategy was sought aggressively is that there is no one-fits-all solution because of the heterogeneous morphology of pulmonary arteries and MAPCAs in these patients.

Weaknesses of the article by van de Woestijne and colleagues ${ }^{1}$ are a small number of patients over a long (30 years) study period, thereby making it impossible to perform sub-analyses, such as comparison between surgical eras or an analysis of results depending on the anatomy of pulmonary arteries and MAPCAs. In addition, information on intraoperative $\mathrm{pRV} / \mathrm{pLV}$ at definitive repair and at follow-up, a critical benchmark for the management of patients with PA/VSD/MAPCA, is absent.

In conclusion, van de Woestijne and colleagues ${ }^{1}$ present a successful staged thoracotomy unifocalization approach to PA/VSD/MAPCA. Given the multiple variations one could have with pulmonary artery and MAPCA anatomy in this anomaly, a midline unifocalization approach may not always be possible. It behooves the surgeon to be familiar with the lateral thoracotomy unifocalization staged approach to $\mathrm{PA} / \mathrm{VSD} / \mathrm{MAPCA}$.

\section{Acknowledgments and Disclosures}

$\mathrm{N} / \mathrm{A}$

\section{Author Contributions}


Yuki Nakamura: Drafting the article, approval of the submitted version

Harold M. Burkhart: Critical revision of the article, approval of the submitted version

\section{References}

1. Van de Woestijne P, Mokhles M, van Beynum I, de Jong P, Wilschut J, Bogers A. Staged correction of pulmonary atresia, ventricular septal defect and collateral arteries. J Card Surg. 2022.

2. Puga FJ, Leoni FE, Julsrud PR, Mair DD. Complete repair of pulmonary atresia, ventricular septal defect, and severe peripheral arborization abnormalities of the central pulmonary arteries. Experience with preliminary unifocalization procedures in 38 patients. J Thorac Cardiovasc Surg. 1989;98:1018-28.

3. Iyer KS, Mee RB. Staged repair of pulmonary atresia with ventricular septal defect and major systemic to pulmonary artery collaterals. Ann Thorac Surg. 1991;51:65-72.

4. Ishibashi N, Shin'oka T, Ishiyama M, Sakamoto T, Kurosawa H. Clinical results of staged repair with complete unifocalization for pulmonary atresia with ventricular septal defect and major aortopulmonary collateral arteries. Eur J Cardiothorac Surg. 2007;32:202-8.

5. Reddy VM, Liddicoat JR, Hanley FL. Midline one-stage complete unifocalization and repair of pulmonary atresia with ventricular septal defect and major aortopulmonary collaterals. J Thorac Cardiovasc Surg. 1995;109:832-44.

6. Mainwaring RD, Patrick WL, Roth SJ, Kamra K, Wise-Faberowski L, Palmon M, Hanley FL. Surgical algorithm and results for repair of pulmonary atresia with ventricular septal defect and major aortopulmonary collaterals. J Thorac Cardiovasc Surg. 2018;156:1194-1204.

7. Mainwaring RD. Midline unifocalization for pulmonary atresia with ventricular septal defect and major aortopulmonary collateral arteries. J Thorac Dis. 2020;12:1263-1273.

8. Brizard CP, Liava'a M, d'Udekem Y. Pulmonary atresia, vsd and mapcas: repair without unifocalization. Semin Thorac Cardiovasc Surg Pediatr Card Surg Annu. 2009:139-44.

9. d'Udekem Y, Alphonso N, Nørgaard MA, Cochrane AD, Grigg LE, Wilkinson JL, Brizard CP. Pulmonary atresia with ventricular septal defects and major aortopulmonary collateral arteries: unifocalization brings no long-term benefits. J Thorac Cardiovasc Surg.2005;130:1496-502.

10. Soquet J, Liava'a M, Eastaugh L, Konstantinov IE, Brink J, Brizard CP, d'Udekem Y. Achievements and limitations of a strategy of rehabilitation of native pulmonary vessels in pulmonary atresia, ventricular septal defect, and major aortopulmonary collateral arteries. Ann Thorac Surg. 2017;103:15191526. 